\title{
A SHAPE GRAMMAR APPROACH TO CLIMATICALLY ADAPTABLE FAÇADE SYSTEMS WITH REAL TIME PERFORMANCE EVALUATION
}

\author{
TUNG NGUYEN, BORIS CERANIC \& CHRISTOPHER CALLAGHAN \\ Department of Architecture and Civil Engineering, University of Derby, UK
}

\begin{abstract}
New computational techniques have been introduced to assist the design of adaptable building façades and to help quantify relationships between the building envelope and the environment. Designers increasingly use generative design approach for form-generation of building envelopes, and the organisation of components over a predefined form. In this research an original shape grammar approach for façade systems generation is proposed, with a rule-based method for the creation and exploration of complex shape composites based upon a set of simple initial shapes and predefined rules of composition. This is in order to explore a form finding of set of different building façade configurations before merging generated data into a simulated process of real-time daylighting and heat gains performance evaluation. The developed models adapt via responding to the data-regulation protocols responsible for sensing and processing building performance data in real time. The research reports on the prototype system development and testing, allowing continuous evaluation of multiple solutions and presenting opportunity for further improvement via multi-objective optimisation, which would be very difficult to do, if not impossible, with conventional design methods.
\end{abstract}

Keywords: kinetic façades, shape grammar, parametric design, performance monitoring, smart building environments.

\section{INTRODUCTION}

Adaptive façade systems can provide healthier internal environment whilst delivering substantial reductions in use of building energy and $\mathrm{CO}_{2}$ emissions. Given the recent advances in the kinetic façades research, they have been identified as promising technological solutions for contributing towards sustainability targets of the 21 st century, on the materials, components and systems level [1].

This research is inspired by traditional patterns and ornaments in Vietnam, seen as an important symbol of cultural heritage, especially in the era of globalisation where many countries are experiencing substantial transformations and beginning to lose links to their long standing historical traditions, including Vietnam. The research investigates how these aspects of spatial culture could be interpreted using shape grammar approach and used in creating novel façade systems that draw their inspiration from Vietnamese vernacular cultural identity, whilst at the same time satisfying modern building performance demands, such as a reduction in the energy consumption and enhanced indoor comfort.

There are numerous studies that research the benefits of grammar-based design generation and implementations [2]-[4], in particular through the concepts of parametric design [5]-[8]. In those hybrid systems, a grammar-based algorithms are responsible for generation of different design iterations, whilst parametric design tends to control alternation to a permitted variations of set parameters. 


\section{SHAPE GRAMMAR PATTERNS DEVELOPMENT}

\subsection{Vietnamese spatial patterns and design}

Patterns are fundamental feature observed in spatial design (interior, architectural, urban and landscape). The word "pattern" is derived from the Latin "pater", or "patronus", meaning father, patron, or protector, resulting in the conception of pattern as a model, example or mould. Modern examples of patterns typically involve repeating units, arrangements or developments of identical or similar elements. Garcia [9] stated that this diversity of meanings delivers multiple types of patterns in the creation, reproduction and evolution of spatial arrangements.

Vietnamese architecture is traditionally perceived as an architecture of relationships (between interior and exterior, between people and the nature, etc.), rather than that of forms and masses. Given its climate, the houses in Vietnam had always been very light, both visually and constructionally (see Fig. 1). They were not built from columns and walls, but from pavilions and covered walkways, lobbies and gardens, all connected though purposely designed routes and passages. Whilst in other countries spaces were often perceived as enclosures formed by substantial walls, spaces in Vietnamese houses were perceived through a sequence of thin screens organised through spatial patterns. In fact, they were often built by using light, movable partitions made of bamboo and wooden frames, such as wooden screens, bamboo folding curtains and sliding doors, always having a certain degree of transparency and permeability. As a result, Vietnamese patterns are open and flexible, emerging as organically generated designs that combine simple shape elements into a more complex composites, informed by the concept of generative design. Given their distinct and
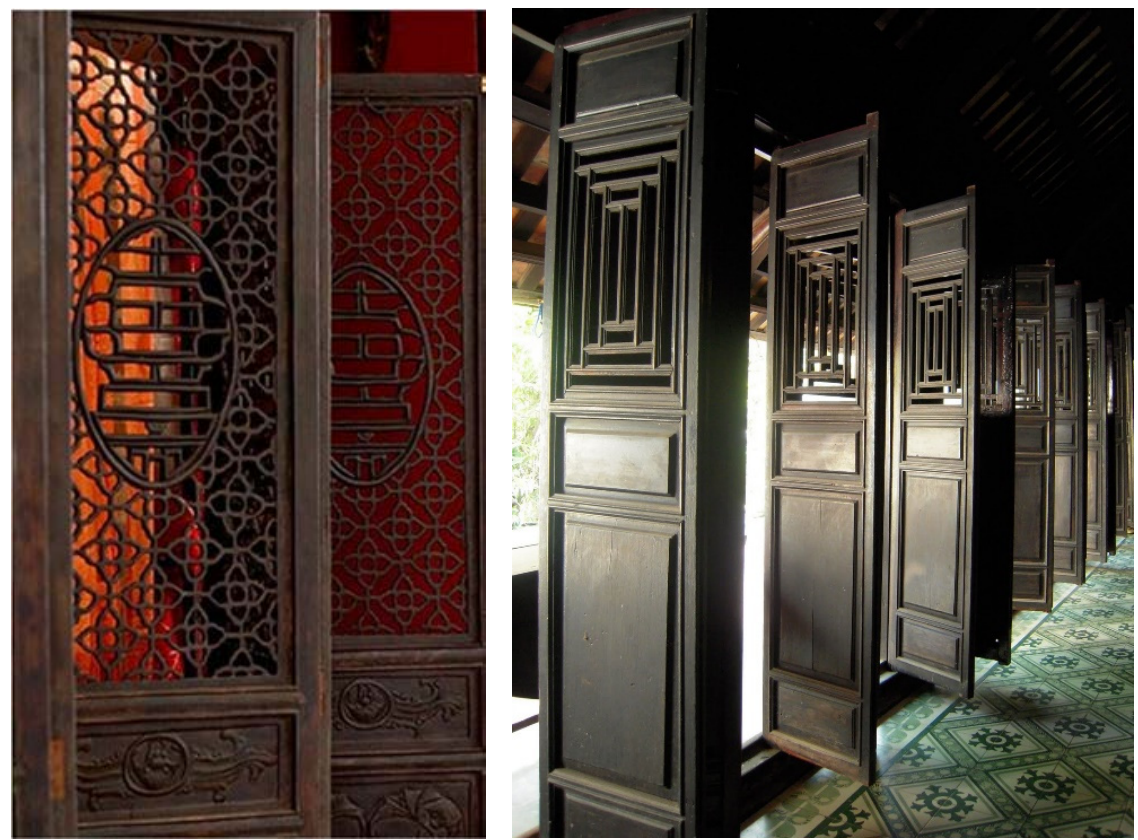

Figure 1: Left: Decorative lattice screens as means of passive ventilation and light control. Right: rotatable door panels with traditional patterns. (Source: Author.) 

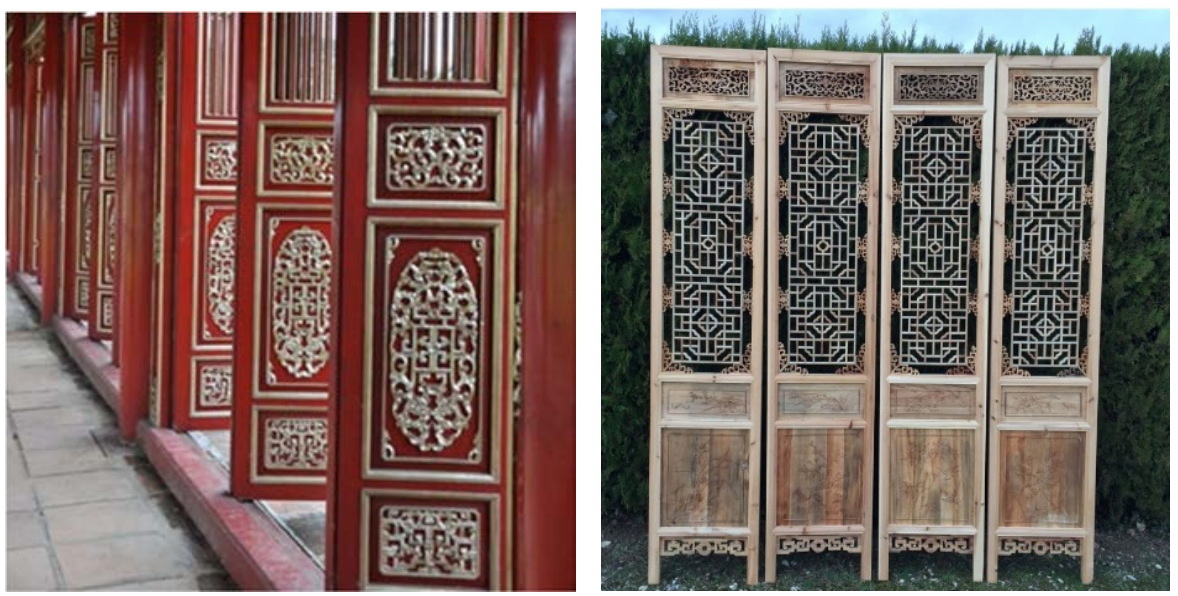

Figure 2: Left: Decorative lattice screens as means of passive ventilation and light control. Right: A movable and foldable curtain wall screen with traditional patterns. (Source: Author.)

broad qualities such as adaptability and repeatability, patterns in Vietnam are depicted as fundamental to structural, aesthetic or energy considerations in design.

With the advent of modern digital technologies new spatial layout theories are emerging, such as generative, algorithmic and parametric design, allowing new types of spatial pattern, sometimes never seen before, to occur. In this research both traditional and modern are merged within the environmental performance context, considering the potential of novel generative patterns design approaches in relation to the design of modern building façade systems and components.

In terms of socio-cultural impact, a compact symbolic form patterns can provide not only information about the cultural history of an ethnic group but also act as catalyst of selfidentification in the society, contributing to cultural and spiritual self-development. They represent a form of universal understanding in a visual symbolic form, a visual archetype of decorative forms that signify cultural identity.

\subsection{Shape grammars development}

Shape grammars (SGs) are a generative design systems that can analyse and produce complex shapes based on a set of initial shapes and series of predefined shape rules. SGs have been used to explain the language of designs such as ornamental art [5], [10], architecture [4], and Islamic patterns [3]. Current implementations have demonstrated how designers take advantages of SGs generative capability [6]. Indeed, shape grammar has been used to capture the cultural gene of designs of for example Chinese ice-ray lattice designs by Stiny [11], the design of Mughul gardens by Stiny and Mitchell [12], Queen Anne style houses by Fleming [8], Taiwanese traditional vernacular residences by Chiou and Krishnamurti [4], traditional Turkish houses by Çağdas [3], classical Ottoman mosques by Şener and Görgül [13], Siza's Malagueira houses by Duarte [6] and by Strobbe in engineering design [14]. Most of these studies concentrate on spatial layout planning or in other words, two-dimensional shapes transformations on a horizontal plane, based on basic input parameters of space such as length, width, etc. 
As defined by [15], "a shape grammar is a quadtuple (VT, VM, R, I), consisting of a finite set of terminal shapes (VT) and marker shapes (VM), a finite set of shape rules (R), and a non empty set of initial shapes (I) that is part of VT $<$ VM. The shapes defined in the set VT $<\mathrm{VM}$ form the basic elements for the definition of shape rules in the set $\mathrm{R}$ and the initial shape I." New and more complex composite shapes are then generated by the rules being applied, recursively and iteratively, to the initial shape. This formation of language of shapes occurs through Euclidean transformations $(\mathrm{t})$, such as translation, rotation, scaling and other linear transformations. Rule application results in "subtracting" the transformed shape A from previous $\mathrm{C}$, and "adding" the transformed replacement shape $\mathrm{B}$ (then-part). This results in a new shape $\mathrm{C}^{\prime}=\mathrm{C}-(\mathrm{A})+\mathrm{t}(\mathrm{B})$.

Stiny [11], one of the original originators of shape grammars, demonstrated that SGs can produce most of the Chinese lattice designs in a very simple and intuitively compelling way (see Fig. 3). He also successfully defined a parametric shape grammar that can describe the constructing process of Chinese Ice-ray patterns. Later, Majewski and Wang [10] and Stiny [11] undertook an algorithmic method to the formation of Chinese lattice patterns and represented them in seventeen types of plane symmetry groups of patterns. This popularity of Chinese lattices patterns research is due to having both cultural meaning and being conducive to the shape grammar computational interpretation.

In this research a shape grammar for typical Vietnamese lattice designs was explored, found on doors and windows used as decorative features, whilst at the same time providing effective means of passive ventilation and light control. They typically are on vertical planes and in this work serve a different purpose - designing and controlling the shading opening (façade aperture) to adapt to change in external climate conditions.
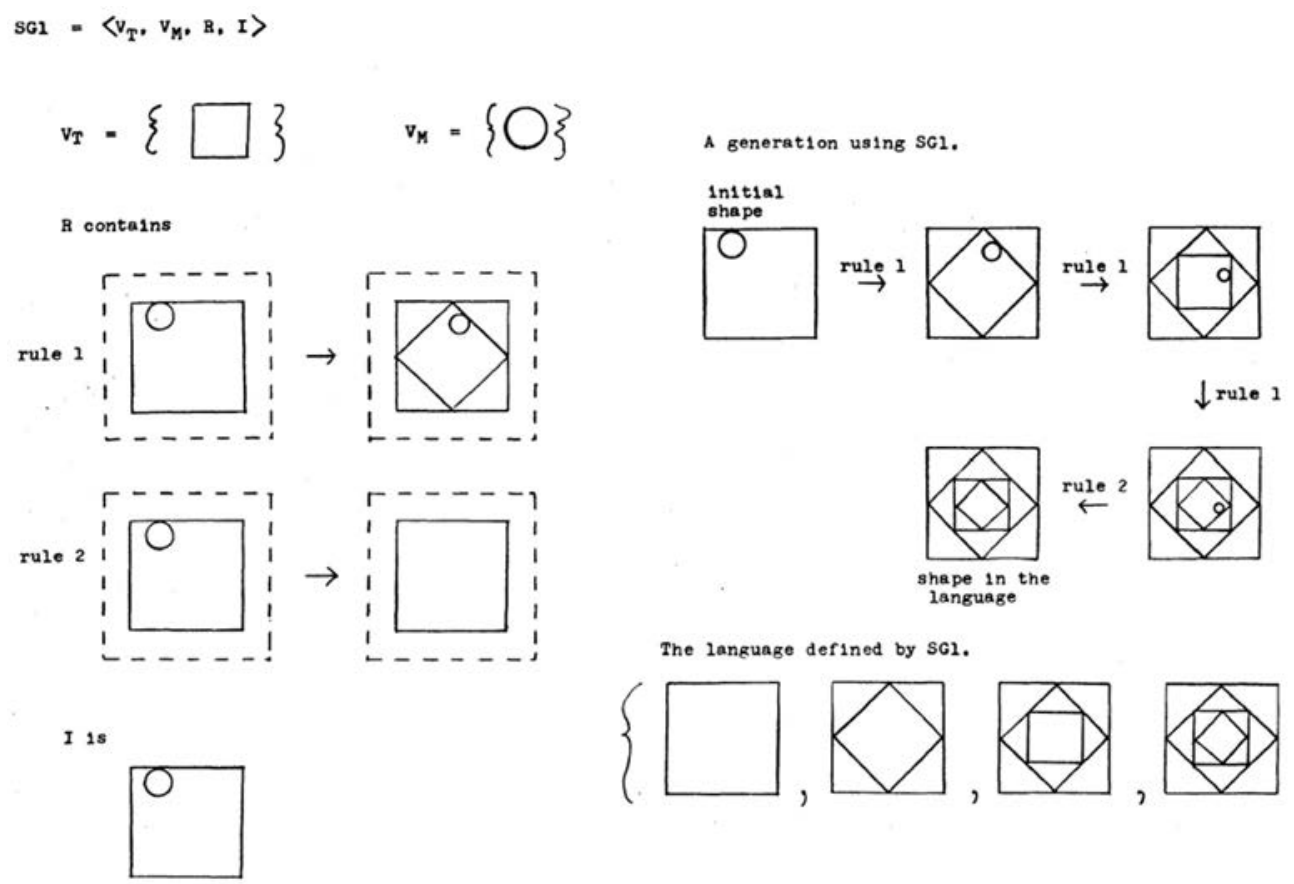

Figure 3: A shape grammar for Inscribed squares [11]. 
Their potential was evaluated in terms of indoor comfort, namely effectiveness of natural daylight control and protection against excessive solar heat gains. Shape Grammar Interpreter (CSourceForge) was used for an initial shape generating process because of its ability to effectively configure rules, produce a multitude of iterations with complex composites and visually display final results (see Fig. 4).

The method proposed in this research is to use shapes extracted from the traditional Vietnamese lattice patterns found in literature, such as I, L, S, H shapes, or combination of them, in a designed shape grammar generation process. This process has two inputs: an initial shape and a shape transformation rule(s), where the rule and its repetition lead to a complex shape composites generation (see Fig. 5). In fact, each node of the lattice represents a shape

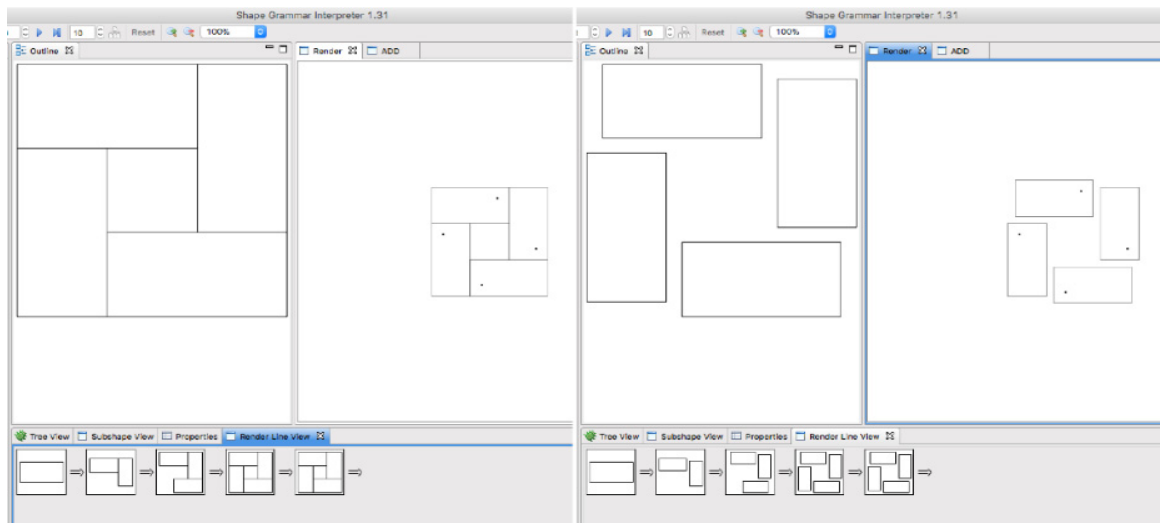

Figure 4: An example of Shape Grammar Interpreter uses straight lines as basic elements for rectangles. (Source: Author.)

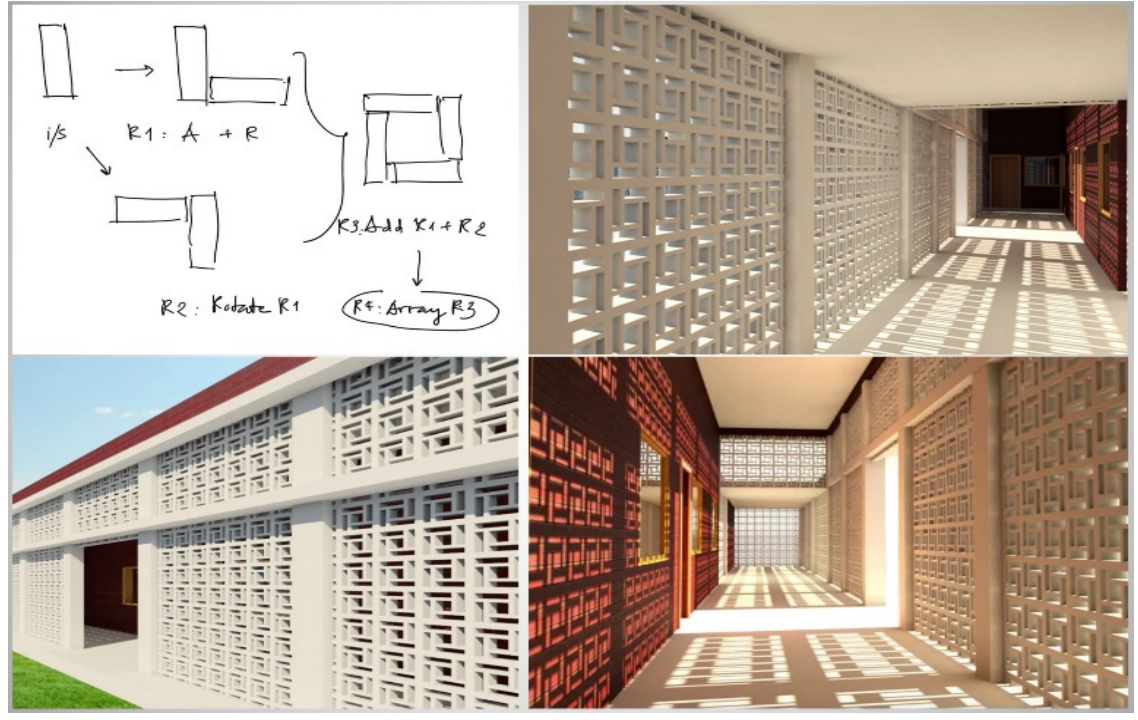

Figure 5: A concept of solar shading device, for a corridor, made of Shape Grammar developed in Fig. 4. (Source: Author.) 
element that is a maximal shape of a combination of such elements including both sub-shapes that are parts of the initial shape description and emergent shapes.

The development begins with defining a vocabulary of two dimensional shapes and their transformation rules. The shapes in these scenarios are made up of the various elements that form the lattices, for example, frame, sub-frame and blocks. Indeed, an initial shape "I" (for rectangle shapes) and 2-d transforming rules, such as move, rotate, add, join and mirror are used. More specific, the generation of a lattice design is based on the manipulation of rectangles as the lowest level constituents. Fig. 5 demonstrates how simple rules can quickly generate complex composites, which could be legibly used in the architectural design as a building components. In particular, the pattern consists of two structures: the global structure and the local structure or the motifs, in which the main evolution process emerges [16].

\section{BIM SDA SBE SYSTEM DESIGN DEVELOPMENT}

\subsection{BIM SDA SBE}

Asset monitoring and evaluating the performance of a building compared to its simulated performance through sustainable design analysis (SDA), is implemented through building management systems (BMS), that are increasingly connected to building information models (BIM). Automating this process through programming and system optimisation leads to intelligent and dynamic buildings, or smart building environments (SBEs) with sufficient reasoning to intelligently control building energy usage (see Fig. 6), whilst ensuring comfort and support for any occupants [17], with façades for example that can adapt to the environmental conditions both around and within the building, in the real time [18].

Developing a prototype BIM-SDA-SBE application [19], involved connecting a building information model created in (C)Autodesk Revit to the sensors in the real world using CAutodesk Dynamo visual programming language [20] to collect and evaluate real time sensor data readings, and then programming the intelligent kinetic façade climatic response, either via controlling the façade system apertures or their shading angles. An Arduino Uno Board has been used to take readings of current room conditions, notably temperature using a DHT22 sensor, and light (lux) using a TSL2591 sensor (see Fig. 7).

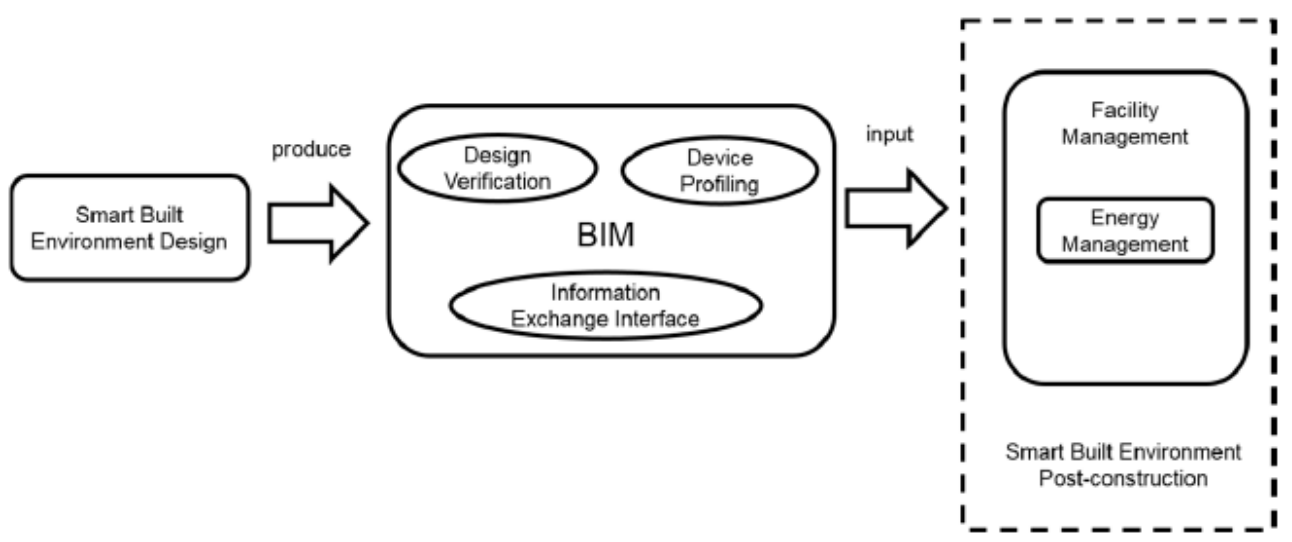

Figure 6: Concept of BIM and SBE integration [17]. 


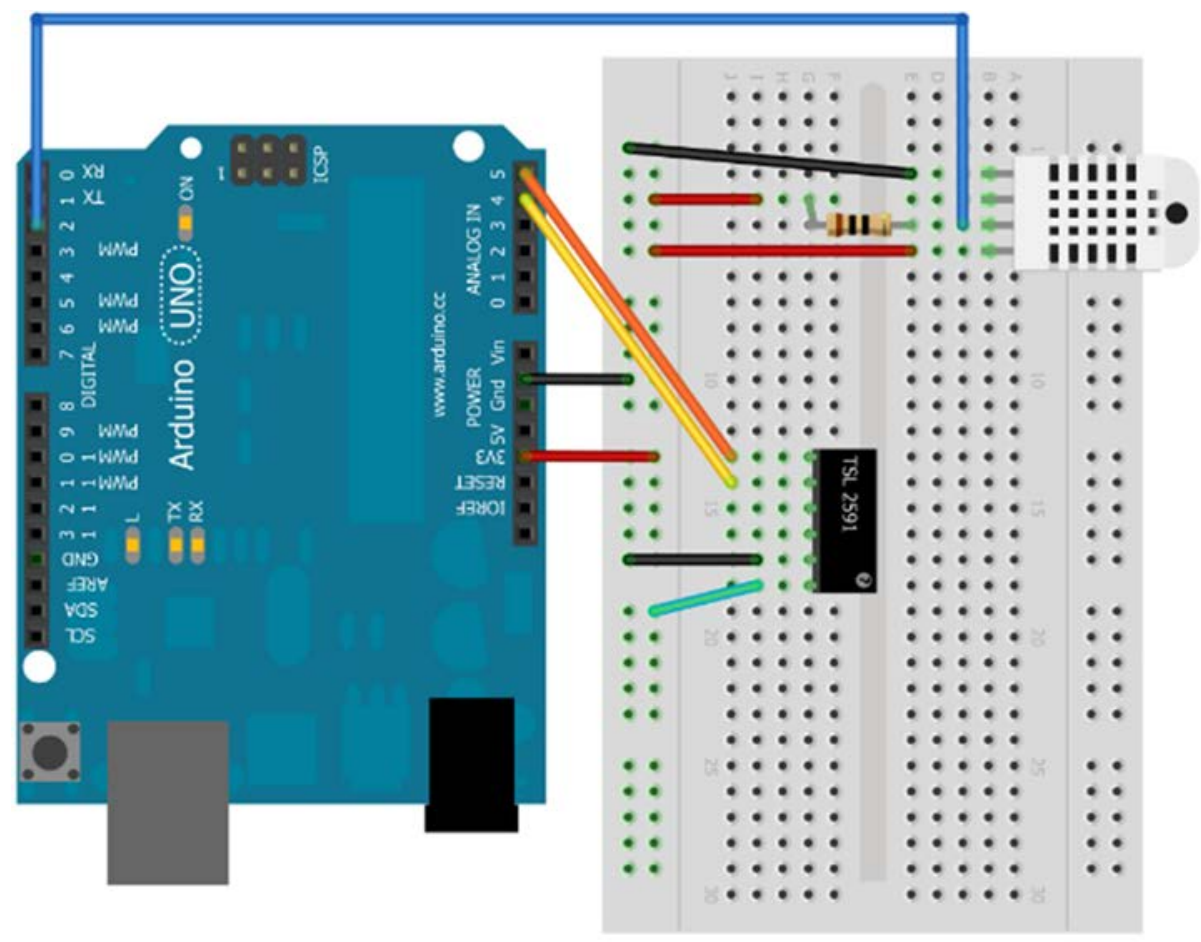

Figure 7: Ardiuno and sensor wiring layout for real time temperature and light data.

(Source: Bruce J, 2011.)

\subsection{System implementation}

To form the bridge between sensors hardware and visual programming environment the research has used Dynamo package called Firefly [21], enabling computer programme to read sensor data real time, in a useable format. Employing an intermediary system to control the flow of data mimics the behaviour of a typical BMS systems, where dedicated subsystems are used to perform different linked functions.

Early evaluation solutions involved applying linear regression to the collected data to predict the future conditions, building a temperature profile for the conditions like those used in the building performance evaluation. The intention with a fully deployed system is to have a simulated temperature profile which would then be modified to reflect the condition data being reported by the sensors in the real time. Developing temperature and reaction profiles for all seasons and conditions enables more informed decisions to be made.

Temperature results are evaluated against the defined comfort conditions (see Fig. 8). Depending on real time sensors readings in relation to $21^{\circ} \mathrm{C}+/-3^{\circ} \mathrm{C}$ adopted thermal template and 300-500 required lux level conditions for this case, the opening angle of the façade shading panels is adjusted. As part of the linear regression approach, data was cumulatively evaluated in 30 minute groupings to determine the likely temperature and light values 30 minutes later. Changing the façade shading panels angle more frequently than every 30 minutes would likely result in disturbance for the occupants without major gains in terms of more effective control of heat gains and access to the daylight. 


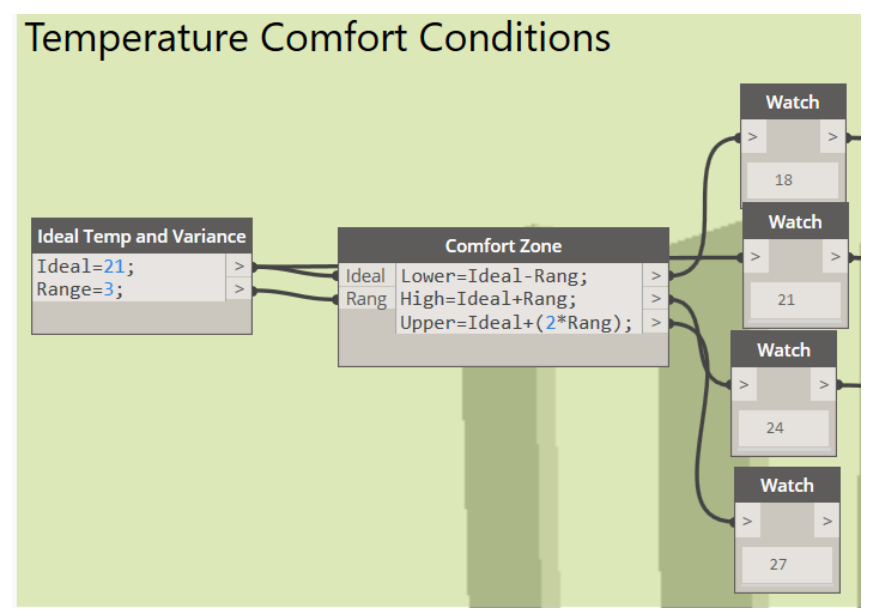

Figure 8: Dynamo graph group for assessing the temperature comfort conditions. (Source: Authors.)

Determining the correct aperture of solar shading device needs to rely not only on the indoor comfort data analysis but also the external climate data simulation. For example, incorporating weather, sun position and room characteristics enables adaptable solutions which react to not only what is typical or predicted, but the actual conditions. This is achieved by linking data and geometry from a building information model in real time (see Fig. 9).

Solar Analysis was carried out with nodes for getting the local weather data and the position of the sun relative to the position of the building being visually programmed in (see Fig. 9). The sun Azimuth and Altitude are carried forwards to the solar control nodes as these give the relative position in relation to the elevation. Relating the Sun Path to the location and orientation of the façade allows the shading angle of the panels to be optimised for each shading array, enabling a curved or multifaceted façade systems to be evaluated more appropriately.

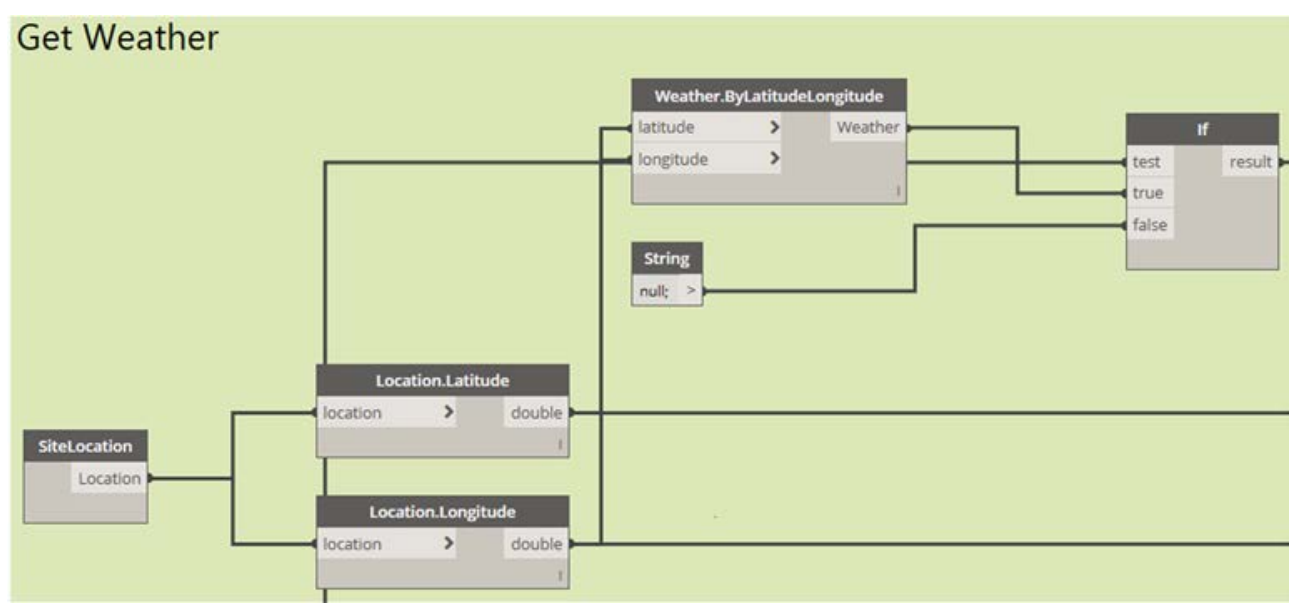

Figure 9: Dynamo graph for getting weather at model location. (Source: Authors.) 
Using the package "Solar Analysis for Dynamo" it was possible to determine the values of solar insolation (see Fig. 10). Calculations are run in parallel for when the openings to a room are unshaded, and when the shading at the determined angle is included [22], [23]. Simulated energy levels can be displayed in a coloured grid pattern giving the designer vision of where the shading is being more effective. Calculating the Net Solar Gain in both shaded and unshaded conditions, gives the heat gains input difference which depending on whether it is positive or negative, will provide the heating or cooling benefit. Recording these values enables adjustment in the calculation to optimise the required temperature reduction.

\section{RESULTS}

Fig. 11 shows the shading angle data plotted against the temperature. In the linear regression scenario, temperature was the main parameter with the light levels adjusting the shading angle accordingly. However, compared to the temperature there is less of a coloration, which could be partly explained by the temperature control factor introduced for temperatures above the upper limit of the comfort zone of $23^{\circ} \mathrm{C}$. From 0 to 110 minutes the temperature was above $23^{\circ} \mathrm{C}$, which resulted in an extra $10 \%$ added by the temperature control factor to the turning angle of shading device to decrease the solar radiation and thus more rapidly prevent overheating.

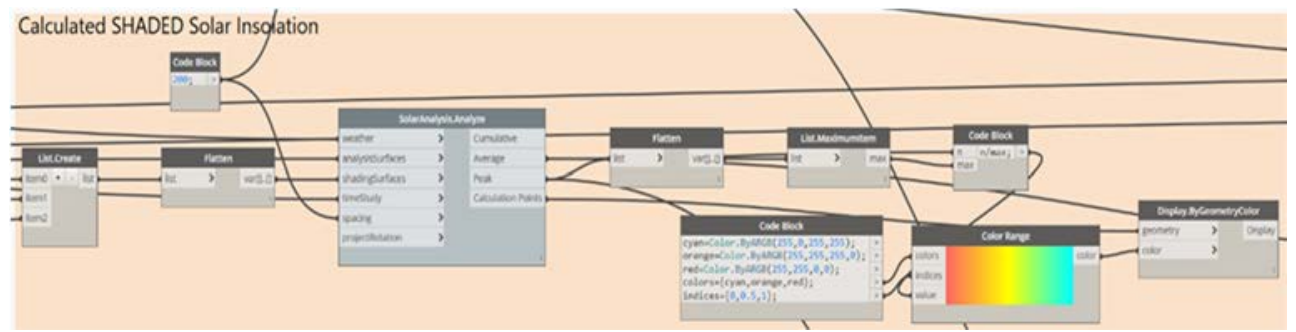

Figure 10: Dynamo Group with calculated data directed to a coloured grid. (Source: Authors.)

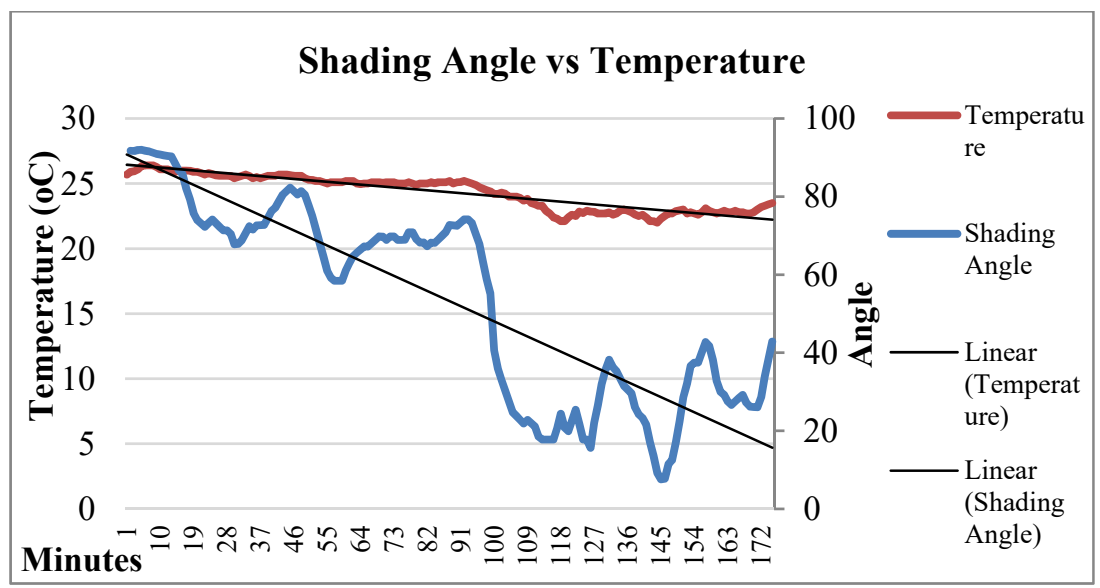

Figure 11: Graph showing shading angle in relation to temperature, including linear trend lines. (Source: Authors.) 
Fig. 12 shows the effectiveness of the shading by comparing shaded and unshaded solutions involving sun, weather and location information. When considered in context of the other heat sources in a room, reducing the overall solar gains can significantly contribute to reduction in overall temperature. In hotter climates where mechanical cooling systems are often employed this should significantly reduce the cooling load required [24].

\section{CONCLUSIONS}

The research integrates smart façade shading systems and intelligent control of their real time response with a unique and vernacularly sensitive approach to their design through application of shape grammar. The latter is conceived as a generative rule-based concept for the creation and exploration of complex shape composites, founded upon set of initial shapes inspired by traditional Vietnamese patterns and their composition rules. The developed prototype model adapt in real time via operating upon communication and data-regulation protocols for sensing and processing building performance information, based on the integration of shape grammar, building information modelling (BIM) and system optimisation. The method for integration of building performance simulation with the building energy management system (oS-BMS) into smart building environments (SBE) based on the open source, has been presented and also been considered, and a prototype structure for their amalgamation has been established.

As reported in the research, the "proof of concept" for the sensor-actuator control has already been developed via BIM based visual programming and virtual sensors with IFC shared parameters, distinctively defining a sensor model and type. Thus virtual objects, in this case kinetic façades systems, are able to self-actuate and regulate light levels and solar heat gains of the actual building component, via its real time sensor-actuator connection. This is based on the results of visual programming algorithms that uses information from a "virtual to real" sensor data within the BIM environment [19].

In its next phase, the research will move onto "proof of prototype" via a scaled physical model investigation. In this phase of prototype construction and testing, the developed SDABIM-SBE integrated building performance monitoring and management system will be examined on its ability to provide an advanced energy management through a deployment of system analysis and optimisation algorithms.

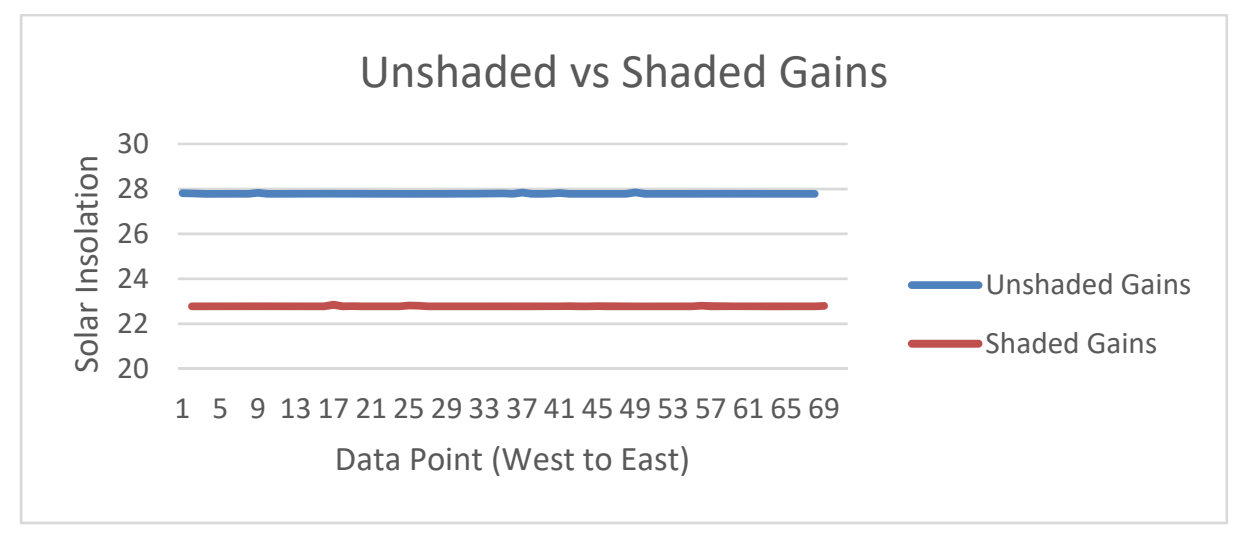

Figure 12: Graph comparing solar insolation in simulated shaded and unshaded conditions. (Source: Authors.) 


\section{REFERENCES}

[1] Loonen, R.C.G.M. et al., Design for façade adaptability-Towards a unified and systematic characterization. Proceedings of the 10th Energy Forum-Advanced Building Skins, Bern: Switzerland, pp. 1274-1284, 2015.

[2] Myers, B.A., Taxonomies of visual programming and program visualization. Journal of Visual Languages and Computing, 1(1), pp. 97-123, 1990.

[3] Çağdas, G., A shape grammar: the language of traditional Turkish houses. Environment and Planning B: Planning and Design, 23(4), pp. 443-464, 1996. DOI: 10.1068/b230443.

[4] Chiou, S.-C. \& Krishnamurti, R., The grammar of Taiwanese traditional vernacular dwellings. Environment and Planning B: Planning and Design, 22(6), pp. 689-720, 1995. DOI: $10.1068 / \mathrm{b} 220689$.

[5] Chase, S.C., Shape grammar implementations: the last 36 years. Shape grammar implementation: from theory to useable software. In Design Computing and Cognition (DCC'10) Workshop, Stuttgart, 2010.

[6] Duarte, J.P., Customizing mass housing: a discursive grammar for Siza's Malagueira Houses. PhD thesis, Department of Architecture, MIT, 2001.

[7] Eleftheria, T. \& Theodoros, T., Energy performance optimization as a generative design tool for nearly zero energy buildings. Procedia Engineering, 180, pp. 11781185, 2017. DOI: 10.1016/j.proeng.2017.04.278.

[8] Flemming, U., More than the sum of parts: the grammar of Queen Anne houses. Environment and Planning B: Planning and Design, 14(3), pp. 323-350, 1987. DOI: 10.1068/b140323.

[9] Garcia, M., Prologue for a history, theory and future of patterns of architecture and spatial design. Architectural Design, 79(6), pp. 6-17, 2009. DOI: 10.1002/ad.974.

[10] Majewski, M. \& Wang, J., A Journey through Chinese Windows and Doors-an introduction to Chinese Mathematical Art, 2015.

[11] Stiny, G., Ice-ray: a note on the generation of Chinese lattice designs. Environment and Planning B: Planning and Design, 4(1), pp. 89-98, 1977. DOI: 10.1068/b040089.

[12] Stiny, G. \& Mitchell, W.J., The grammar of paradise: on the generation of Mughul gardens. Environment and Planning B: Planning and Design, 7(2), pp. 209-226, 1980. DOI: $10.1068 / \mathrm{b} 070209$.

[13] Şener, S.M. \& Görgül, E.A., Shape grammar algorithm and educational software to analyze classic Ottoman mosques. Journal of the Faculty of Architecture, 5(1), pp. 12$30,2008$.

[14] Strobbe, T., Pauwels, P., Verstraeten, R., De Meyer, R. \& Van Campenhout, J., Toward a visual approach in the exploration of shape grammars. Artificial Intelligence for Engineering Design, Analysis and Manufacturing, 29(4), pp. 503-512, 2015. DOI: 10.1017/s0890060415000475.

[15] Liu, Y., Zhang, K., Kong, J., Zou, Y. \& Zeng, X., Spatial specification and reasoning using grammars: from theory to application. Spatial Cognition \& Computation, 18(4), pp. 315-340, 2018. DOI: 10.1080/13875868.2018.1490290.

[16] Singh, V. \& Gu, N., Towards an integrated generative design framework. Design Studies, 33(2), pp. 185-207, 2012. DOI: 10.1016/j.destud.2011.06.001.

[17] Zhang, J., Seet, B. \& Lie, T.T., Building information modelling for smart built environments. Buildings, 5(1), pp. 100-115, 2015. DOI: 10.3390/buildings5010100.

[18] Velikov, K. \& Thun, G., Design and Construction of High-Performance Homes: Building Envelopes, Renewable Energies and Integrated Practice, Responsive 
Building Envelopes: Characteristics and Evolving Paradigms, Routledge: New York, 2013.

[19] Ceranic, B., Cox, A. \& Beardmore, J., Rapid Deployment Modular Building Solutions and Climatic Adaptability: Case Based Study of a Novel Approach to "Thermal Capacity on Demand" and Building Management Systems. Energy and Buildings, 167, pp. 124-135, 2018. DOI: 10.1016/j.enbuild.2018.01.044.

[20] Halbert, D.C., Programing by example, in: Brad A. Myers. Taxonomies of Visual Programming and Program Visualization, 1, 97-123, 1990.

[21] Kensek, KM., Integration of Environmental Sensors with BIM: case studies using Arduino, Dynamo, and the Revit API. Informes de la Construcción, 66(536), e044, 2014. DOI: $10.3989 /$ ic. 13.151.

[22] Perez, R., Ineichen, P., Seals, R., Michalsky, J. \& Stewart, P., Modeling daylight availability and irradiance components from direct and global irradiance. Solar Energy, 44(5), pp. 271-289, 1990. DOI: 10.1016/0038-092x(90)90055-h.

[23] Szokolay, S., Introduction to Architectural Science, Routledge: London, p. 352, 2014.

[24] Tzempelikos, A. \& Athienitis, A., The impact of shading design and control on building cooling and lighting demand. Solar Energy, 81(3), pp. 369-382, 2007. DOI: 10.1016/j.solener.2006.06.015. 